\title{
Determination of Punicalagins Content, Metal Chelating, and Antioxidant Properties of Edible Pomegranate (Punica granatum L) Peels and Seeds Grown in Morocco
}

\author{
Talal Sabraoui $\mathbb{D D}^{1}{ }^{1}$ Taleb Khider, ${ }^{2}$ Boubker Nasser, ${ }^{1}$ Rabiaa Eddoha, ${ }^{1}$ \\ Abderrahman Moujahid, ${ }^{1}$ Maryam Benbachir, ${ }^{1}$ and Abdelkhalid Essamadi ${ }^{1}{ }^{1}$ \\ ${ }^{1}$ Faculty of Sciences and Technology Laboratory of Biochemistry \& Neurosciences, Applied Biochemistry and Toxicology Team, \\ Hassan First University, 26000 Settat, Morocco \\ ${ }^{2}$ Food Chemistry, Department of Chemistry and Pharmacy, Emil Fischer Center, Friedrich-Alexander Universitât Erlangen- \\ Nürnberg (FAU), Nikolaus-Fiebiger-Straße 10, 91058, Germany
}

Correspondence should be addressed to Talal Sabraoui; t.sabraoui@uhp.ac.ma and Abdelkhalid Essamadi; essamadi@uhp.ac.ma Received 8 June 2020; Revised 16 August 2020; Accepted 1 September 2020; Published 22 September 2020

Academic Editor: Jaime Yanez

Copyright (C) 2020 Talal Sabraoui et al. This is an open access article distributed under the Creative Commons Attribution License, which permits unrestricted use, distribution, and reproduction in any medium, provided the original work is properly cited.

\begin{abstract}
Pomegranate (Punica granatum L) is widely cultivated in the Mediterranean countries especially in Morocco. Pomegranate peel and seed contain considerable amounts of phenolic compounds with antioxidant activity. The aim of the present study was to phytochemically characterize the pomegranate peels and seeds obtained from three Moroccan provinces, using UHPLC-DAD. In addition, total phenolic content (TPC), total flavonoid contents (TFC), and metal chelating of pomegranate peel were also evaluated. The results showed that pomegranate peel possesses the highest phenolic (TPC: $224.39 \mathrm{mg}$ GAE/g dw) and flavonoid (TFC: $62.64 \mathrm{mg}$ rutin $/ \mathrm{g} \mathrm{dw}$ ) contents. Punicalagin- $\beta$ and punicalagin- $\alpha$, are the abundant compounds found in peel: $216.36 \pm$ $9.94 \mathrm{mg} / \mathrm{g}, 154.94 \pm 5.21 \mathrm{mg} / \mathrm{g}$, respectively. Pomegranate peels showed significantly $(p<0.05)$ high antioxidant activity 1 diphenyl-2-picrylhydrazyl (DPPH) $\mathrm{EC}_{50}: 42.71 \pm 0.04 \mu \mathrm{g} / \mathrm{mL}, 2.2^{\prime}$-Azino-bis(3-Ethylbenzothiazoline-6-Sulfonic Acid) (ABTS) $\mathrm{EC}_{50}: 62.15 \pm 0.01 \mu \mathrm{g} / \mathrm{mL}$ ), and chelating activity (FRAP $1.85 \pm 0.00 \mathrm{mg}$ ascorbic acid equivalents $/ 100 \mathrm{~g}, \mathrm{Fe}^{2+}: 2.52 \pm 0.01 \mu \mathrm{mol}$ EDTA equivalents/g dw) compared to seeds. A positive correlation between antioxidant activity and total phenolic was found. According to achieved results, high antioxidant capacity of pomegranate extracts, especially peel, shed light to further use as natural food preservatives. Pomegranate peel could be used for the fortification of food with fiber by introducing it in dietary, as well as in health applications due to its higher antioxidant capacity.
\end{abstract}

\section{Introduction}

Pomegranate (Punica granatum. L) is a highly appreciated edible fruit tree in the world. The source of pomegranate is related to central Asia, from Iran to China and Eastern India [1]. Nevertheless, the cultivation of the fruit has spread to Mediterranean countries like Turkey and North Africa. Presently, the commercial cultivation of pomegranate is mainly concentrated in the Mediterranean countries followed by Asian countries [2]. Different cultures as ancient Egyptians and Indians used pomegranate in traditional medicine for many centuries [3].
In Morocco, dried peel of pomegranate is still used until today as a natural traditional treatment of diarrhea and dental plaque. The therapeutic potential of pomegranate has pushed both consumers and researchers to increase the interest in pomegranate bioactive compounds. Indeed, many studies have been conducted in the last few decades on the phytochemicals contents and antioxidant potential of pomegranate [1, 4-11]. Due to its sweet flavor, arils are the most edible part of pomegranate. However, data from literature demonstrated that the pomegranate peel had the highest antioxidant capacity comparing to seed and juice [12, 13]. Today it is accepted that pomegranate peel demonstrates 
good pharmacological properties, such as antioxidative [13], anticancer [14], and antidiabetic [15]. The comestible part of the fruit is particularly the arils. Considered a waste products, peel could have useful applications in meat conservation [16] and food industry [17]. Phenolic compounds as anthocyanins, punicalagin, and ellagic acid can represent about $50 \%$ of the fruit [9]. In fact, the peel is considered a good natural source of phenolic compounds [10], many studies have shown a high correlation between the antioxidant activity and amounts of phenolic compounds [12]. Pomegranate seed represented about $20 \%$ of the fruit and demonstrated interesting therapeutic applications and a good source biocompounds and antioxidants [18]. A study by Shaban et al. [19] revealed that the administration of pomegranate seed oil showed a significant protective effect against diethylnitrosamine (DEN) induced oxidative stress and apoptosis in hepatocytes. The benefits of pomegranate seed are mainly associated with the content of conjugated linolenic acids [20,21].

Moroccan production of pomegranate overreaches 58,000 tones in a total area of 4,625 hectares; Tadla Azilal is the leading region in Morocco with a production of 28,000 $\mathrm{t}$ in an area of 1,410 hectares [21]. Studies on Moroccan pomegranate fruit have focused on genetic diversity [22], or physicochemical characteristics, total phenolic, and the antioxidants of juice $[23,24]$. To the best of our knowledge, this is the first study characterizing the phenolic compounds and antioxidants activity of the Moroccan pomegranate peel and seed extracts grown in three distinct provinces: Beni Mellal, Settat, and Berkane. Given the wide spectrum of health-promoting activities of pomegranate peel, this work aimed to prepare methanolic fractions from peels and seeds of pomegranate, evaluate their antioxidant activity, and establish a correlation between phenolic compounds and antioxidants capacity.

\section{Materials and Methods}

2.1. Chemicals. All chemicals and reagents were purchased from Sigma-Aldrich chemistry (Germany); punicalagin ( $\geq 98 \%$ ), ellagic acid ( $\geq 98 \%$ ), and gallic acid (97.5\%) were purchased from Sigma-Aldrich (Taufkirchen, Germany).

2.2. Fruit Samples and Extraction Procedures. Mature pomegranate fruits, variety "SEFRI", were purchased from three geographical origins Beni Mellal, Settat, and Berkane provinces of Morocco. Fruits were manually peeled, collected peels and seeds were rinsed with distilled water and dried in an oven (Binder, BD 56 Germany) with air circulation at $40^{\circ} \mathrm{C}$. Samples were ground in a laboratory grinder and passed through a sieve of $0.25 \mu \mathrm{m}$ (Retsch, Germany). The dried sample was then stored at $20^{\circ} \mathrm{C}$ until further use. The peel and seed powder $(10 \mathrm{~g})$ were extracted with $60 \mathrm{~mL}$ of methanol by magnetic stirring at room temperature for 24 hours. The extracts were filtered using Whatman no.41 filter paper. The residue was reextracted with $50 \mathrm{~mL}$ of methanol and filtered. The pool of extracts were concentrated under vacuum at $40^{\circ} \mathrm{C}$ (rotary evaporator Buchi R-210, Switzerland) [19].
2.3. Total Phenols and Flavonoid Content. The total phenolic content was determined according to the method of FolincCiocalteu [25]. Briefly, pomegranate extracts $(0.2 \mathrm{mg})$ were mixed with $0.1 \mathrm{~mL}$ of 10 -fold diluted Folin-Ciocalteu reagent. After $5 \mathrm{~min}, 0.8 \mathrm{~mL}$ of sodium carbonate $7.5 \%(w / v)$ solution was added to the mixture and incubated for $30 \mathrm{~min}$ at $30^{\circ} \mathrm{C}$ then absorbance of the solution was read at $765 \mathrm{~nm}$ using Genesys-5 UV-visible spectrophotometer. Results were expressed as mg of gallic acid equivalents (GAE) per gram of dry weight (dw). The determination of flavonoid content is based on the formation of the complex flavonoid and aluminum [26]. Briefly, $0.5 \mathrm{~mL}$ of both peel and seed extract was mixed $0.5 \mathrm{~mL}$ aluminum chloride $2 \%$, then $3 \mathrm{~mL}$ of potassium acetate 5\% (Merck, Germany) was added, after $40 \mathrm{~min}$ at room temperature, and the absorbance was measured at $415 \mathrm{~nm}$. Results are expressed as rutin equivalent in $\mathrm{mg} / \mathrm{g}$.

2.4. UHPLC-DAD Quantitative Analysis. Quantification of phenolic compounds was performed using ultrahighperformance liquid chromatography equipped with hyphenated diode array detection (UHPLC-DAD; Thermofisher, Idstein, Germany). The detection wavelengths of $280 \mathrm{~nm}$ and $520 \mathrm{~nm}$ were selected. A HSS-T3 $1.7 \mu \mathrm{m}$ column (50 mm $\times 2.1 \mathrm{~mm})$ (Waters, USA) was used. $10 \mu \mathrm{L}$ of sample was injected, and $22^{\circ} \mathrm{C}$ temperature of column was ensured throughout the analytical process. Eluent A consisted of $0.1 \%$ formic acid in MilliQ water and eluent B (methanol). The flow rate was $0.3 \mathrm{~mL} / \mathrm{min}$. The gradient was optimized as follows: $1-5$ minutes $1-5 \% \mathrm{~B} ; 5-10$ minutes $5-25 \% \mathrm{~B} ; 10$ 13 minutes $25-95 \%$ B; $13-16$ minutes $95 \%$ B. The standard polyphenols: gallic acid, $(\alpha, \beta)$-punicalagin, and ellagic acid were mixed and dissolved in methanol to concentrations of $60 \mu \mathrm{g} / \mathrm{mL}, 1000 \mu \mathrm{g} / \mathrm{mL}$, and $300 \mu \mathrm{g} / \mathrm{mL}$, respectively. Then, the phenolic compounds were quantified using the UHPLC Chromeleon software. For this purpose, calibration curves were prepared from gallic acid: $0.03-60 \mu \mathrm{g} / \mathrm{mL} ; r^{2}=0.9988$; ellagic acid: $0.03-300 \mu \mathrm{g} / \mathrm{mL} ; \quad r^{2}=0.999$, punicalagin- $\alpha$ : $0.16-1000 \mu \mathrm{g} / \mathrm{mL} ; \quad r^{2}=0.9995$ and punicalagin- $\beta$ : 0.16 $1000 \mu \mathrm{g} / \mathrm{mL} ; r^{2}=0.9992$ [27].

2.5. DPPH Assay. DPPH assay was measured according to the method described by Singh et al. [25]. Different concentrations of pomegranate peel and seed extracts were placed in different tubes, $5 \mathrm{~mL}$ of a $0.1 \mathrm{mM}$ methanolic solution of DPPH was added to $100 \mu \mathrm{L}$ of every extract, and then, the tubes were shaken vigorously. A positive control (methanol instead of the sample) was prepared, and methanol only was used to zero the spectrophotometer. The tubes were allowed to stand at room temperature for about $30 \mathrm{~min}$. The change of absorbance was measured at $517 \mathrm{~nm}$. Radical scavenging capacity was estimated as percent of DPPH and expresses as a function of the sample concentration using the following formula: radical scavenging activity $(\%)=($ control OD - sample OD/control OD) $\times 100$. The antioxidant activity was calculated as the effective concentration of a sample required to decrease the absorbance of the positive control by $50 \%\left(\mathrm{EC}_{50}\right)$. 
TABLe 1: Qualitative-quantitative analyses of the polyphenolic fraction in selected extracts.

\begin{tabular}{cccccccc}
\hline & & $\begin{array}{c}\text { Total phenolic } \\
(\mathrm{mg} \mathrm{GAE} / \mathrm{g})\end{array}$ & $\begin{array}{c}\text { Total flavonoids } \\
(\mathrm{mg} \mathrm{RE} / \mathrm{g})\end{array}$ & $\begin{array}{c}\text { Punicalagin- } \beta \\
(\mathrm{mg} / \mathrm{g})\end{array}$ & $\begin{array}{c}\text { Punicalagin- } \alpha \\
(\mathrm{mg} / \mathrm{g})\end{array}$ & $\begin{array}{c}\text { Ellagic acid } \\
(\mathrm{mg} / \mathrm{g})\end{array}$ & $\begin{array}{c}\text { Gallic acid } \\
(\mathrm{mg} / \mathrm{g})\end{array}$ \\
\hline \multirow{4}{*}{ Peel } & Settat & $223.21 \pm 15^{\mathrm{a}}$ & $52.12 \pm 1.36^{\mathrm{a}}$ & $200.30 \pm 5.29^{\mathrm{a}}$ & $128.57 \pm 2.74^{\mathrm{a}}$ & $34.43 \pm 0.91^{\mathrm{a}}$ & $2.14 \pm 0.00^{\mathrm{a}}$ \\
& Beni Mellal & $224.39 \pm 3^{\mathrm{a}}$ & $62.63 \pm 3.23^{\mathrm{b}}$ & $200.21 \pm 8.78^{\mathrm{a}}$ & $130.66 \pm 4.58^{\mathrm{b}}$ & $35.00 \pm 0.77^{\mathrm{a}}$ & $1.86 \pm 0.05^{\mathrm{b}}$ \\
& Berkane & $204.58 \pm 1.96^{\mathrm{a}}$ & $46.17 \pm 2.18^{\mathrm{a}}$ & $216.36 \pm 9.94^{\mathrm{a}}$ & $154.94 \pm 5.2^{\mathrm{a}}$ & $32.14 \pm 0.53^{\mathrm{b}}$ & $2.23 \pm 0.18^{\mathrm{c}}$ \\
\multirow{4}{*}{ Seed } & Settat & $63.34 \pm 0.7^{\mathrm{b}}$ & $2.11 \pm 0.28^{\mathrm{c}}$ & $1.75 \pm 0.64^{\mathrm{b}}$ & $2.93 \pm 0.37^{\mathrm{c}}$ & $1.60 \pm 0.27^{\mathrm{c}}$ & $0.14 \pm 0.00^{\mathrm{d}}$ \\
& $\begin{array}{c}\text { Beni Mellal } \\
\text { Bene }\end{array}$ & $67.85 \pm 1.98^{\mathrm{b}}$ & $1.76 \pm 0.02^{\mathrm{c}}$ & $1.10 \pm 0.4^{\mathrm{b}}$ & $1.15 \pm 0.12^{\mathrm{d}}$ & $1.47 \pm 0.21^{\mathrm{c}}$ & $0.13 \pm 0.00^{\mathrm{e}}$ \\
& Berkane & $62.17 \pm 3.26^{\mathrm{b}}$ & $1.94 \pm 0.00^{\mathrm{c}}$ & $1.30 \pm 0.27^{\mathrm{b}}$ & $1.44 \pm 0.03^{\mathrm{e}}$ & $1.17 \pm 0.04^{\mathrm{c}}$ & $0.20 \pm 0.04^{\mathrm{f}}$ \\
\hline
\end{tabular}

Different letters of within the same column is indicating significant differences at $p<0.05$. All data are expressed as mean \pm SD of at least three replicates of each sample. GAE: gallic acid equivalents; RE: rutin equivalents.

2.6. ABTS Assay. ABTS assay was based on the method of Ramos et al. [28] with slight modifications. Briefly, the radical ABTS solution was prepared by mixing equal volume of ABTS stock solution $7 \mathrm{mM}$ with $2.45 \mathrm{mM}$ of potassium persulfate. The mixture was allowed to stand for 16 hours at room temperature in the dark. Before been used, different concentrations of this solution in acetate buffer $(\mathrm{pH} 4.6$ $50 \mathrm{mM}$ ) were prepared to obtain an absorbance of $0.700 \pm$ 0.02 at $734 \mathrm{~nm}$. The assay was performed in a 96-well microplate. Hence, $150 \mu \mathrm{L}$ of the diluted sample was added in the plate followed by adding $150 \mu \mathrm{L}$ of the ABTS solution. Absorbance was measured after $6 \mathrm{~min}$ by spectrophotometer (Synergy HT, Bio-Tek Instruments, Winooski, VT, USA). ABTS scavenging percentage was calculated using the following equation: ABTS scavenging $(\%)=($ control OD - sample $\mathrm{OD} /$ control $\mathrm{OD}) \times 100$. The $\mathrm{EC}_{50}$ values were calculated from standard curves.

2.7. FRAP Assay. Determination of the ferric reducing antioxidant power (FRAP) was based on the method by Oyaizu et al. [29]. $500 \mu \mathrm{L}$ of peel and seed was added to $1.25 \mathrm{~mL}$ of phosphate buffer (0.2 M, pH 6.6); $1.25 \mathrm{~mL}$ of ferricyanide potassium is added to each tube, followed by $1.25 \mathrm{~mL}$ of trichloro-acetic acid $(10 \% v / v)$. The mixture is incubated at $50^{\circ} \mathrm{C}$ for $15 \mathrm{~min}$ and diluted in distilled water $(1: 2, v / v)$, and $0.25 \mathrm{~mL}$ of ferric chloride $1 \%$ was added. The absorbance was measured at $700 \mathrm{~nm}$ and results are expressed as equivalent $\mathrm{mg}$ ascorbic acid equivalent (AAE) per $100 \mathrm{~g}$ of DW.

2.8. $\mathrm{Fe}^{2+}$ Chelating Activity Assay. Pomegranate peel and seed extracts of ferrous ions $\mathrm{Fe}^{2+}$ were measured using the method described by Dinis et al. [30]. Briefly, $0.5 \mathrm{~mL}$ of extract at different concentrations was added to $1.6 \mathrm{~mL}$ of distilled water, and $0.05 \mathrm{~mL}$ of $\mathrm{FeCl}_{2}(2 \mathrm{mM})$ was added, followed by adding $0.1 \mathrm{~mL}$ Ferrozine $(5 \mathrm{mM})$. The mixture is incubated at room temperature for $10 \mathrm{~min}$, complex of $\mathrm{Fe}^{2+}$, and Ferrozine complex was measured at $562 \mathrm{~nm}$. The chelating activity of the extract was calculated using the following equation: metal chelating activity $(\%)=(\mathrm{OD}$ control $-\mathrm{OD}$ sample/OD control $) \times 100$. The results were expressed as $\mu \mathrm{mol}$ of EDTA equivalent/g of dry weight.

2.9. Statistical Analysis. Data were analyzed by the IBM SPSS V 23 software. One-way (ANOVA) and post hoc Tukey's HSD tests were used for multiple comparisons. Differences were considered significant at $p<0.05$. Correlation values between experimental data were evaluated using Pearson's coefficient.

\section{Results and Discussion}

3.1. Total Phenolic and Total Flavonoid Content in Pomegranate Peels and Seeds. Pomegranate is one of the richest fruits with phenolic compounds, namely punicalagin, anthocyanins, and punicalin gallic and ellagic acids. Yet, a lack of information exists about the phenolic content of peel and seed of Moroccan pomegranate. Previous studies showed methanol as the solvent to achieve maximum yield of extract and maximum phenolic content from different parts of the fruit [30-32]. In our study, peel and seed extracts from pomegranate fruits grown in three different Morocco provinces were studied. The yields of methanolic extracts obtained in fruits from Beni Mellal, Settat, and Berkane provinces were $36 \%, 43 \%$, and $53 \%$; and $16 \%, 22 \%, 21 \%$ in peel and seed, respectively. These data are comparable to values found by Pagliarulo et al. [33] in peel using 50\% ethanol/water $(v / v)$, and higher than data reported by Singh et al. [25] when using methanol as solvent 9.38 and $8.62 \%$ in peel and seed, respectively. Differences in yields could be related to sample particle size. A study by Wang et al. [32] suggest that smaller sample particles size increased the extraction rate. The concentrations of total phenolic content found in Beni Mellal, Berkane, and Settat peel were 3.52, 3.29, and 3.30-folds higher than the content determined in seeds, respectively (Table 1). In fact, other works reported similar results $[13,34,35]$, confirming that the highest phenolic compounds are in the pomegranate peel. Thus, the total peel polyphenols ranged from 204.59 to $224.39 \mathrm{mg} \mathrm{GAE} / \mathrm{g} \mathrm{dw}$, slightly lower than those found by $\mathrm{Li}$ et al. [3]: $249.4 \mathrm{mg}$ GAE/g dw of pomegranate peel extract in comparison with pomegranate pulp extract. Khalil et al. [36] studied the punicalagin contents and antioxidant activity after juice extraction obtaining a phenolic content of $289.40 \mathrm{mg} \mathrm{GAE} / \mathrm{g}$ $\mathrm{dw}$ in peel methanolic extract. These variations in the values in the total phenolic content could be due to the varietal difference. Seed phenolic compounds were evaluated between 62.17 and $67.86 \mathrm{mg} \mathrm{GAE} / \mathrm{g} \mathrm{dw}$, consistent with the data reported by Orak et al. [11] where the phenolic compounds of seed using methanol as a solvent ranged from 54.48 to $63.43 \mathrm{mg} \mathrm{GAE} / \mathrm{g}$. While, other study reported lower 


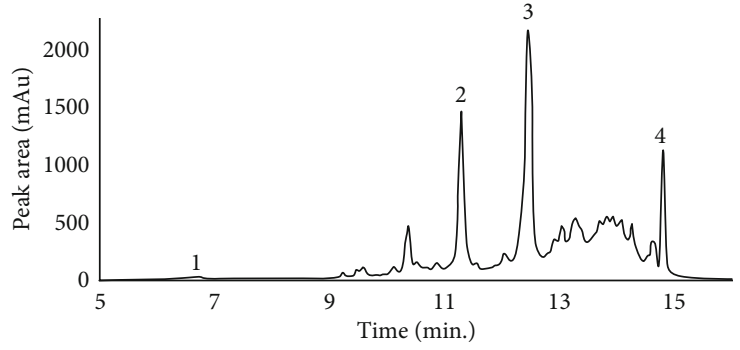

(a)

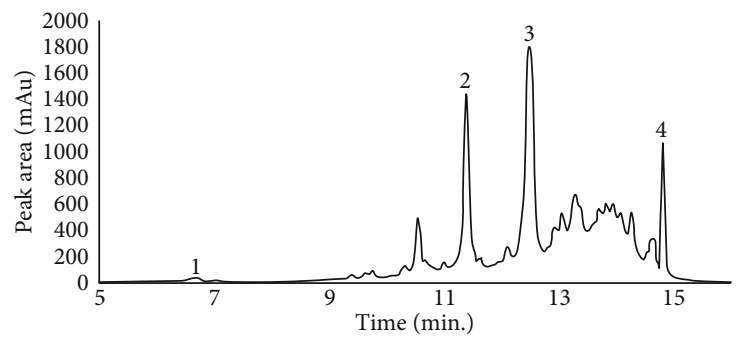

(c)

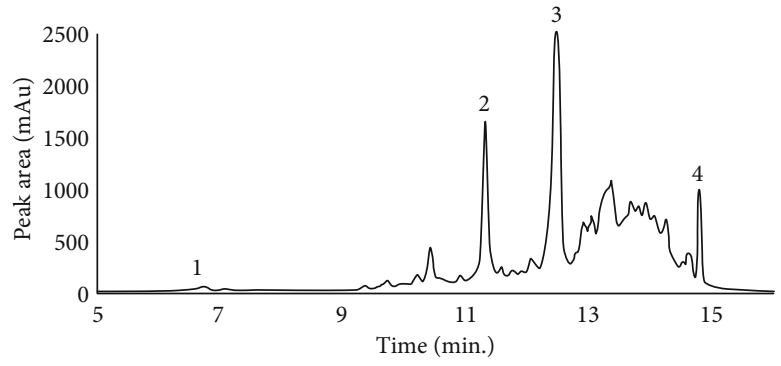

(e)

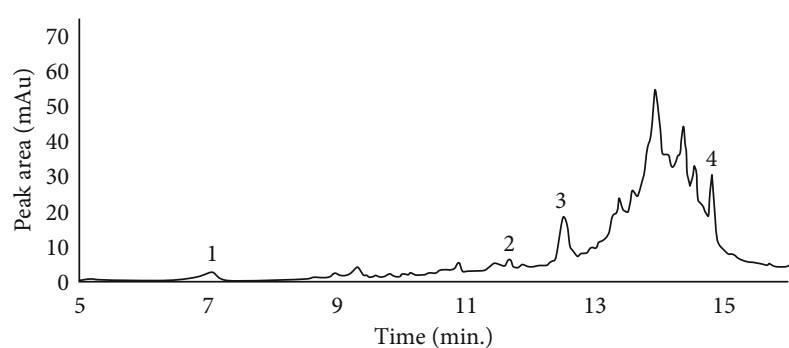

(b)

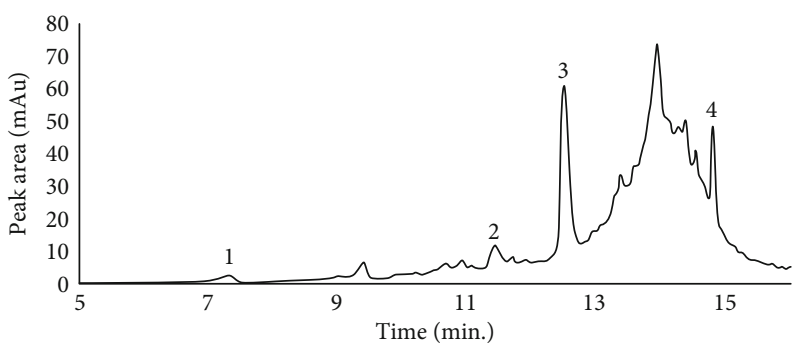

(d)

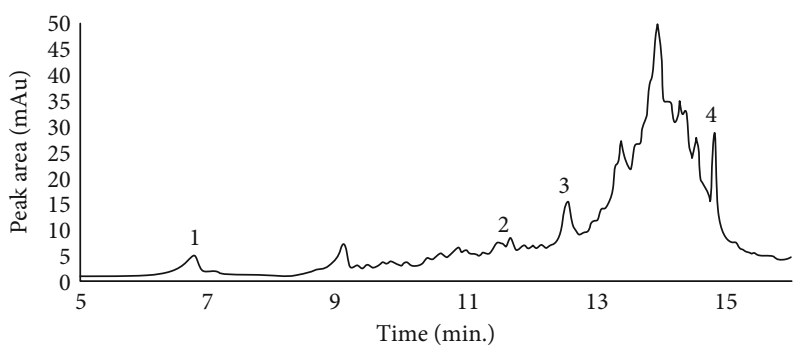

(f)

FIGURE 1: UHPLC-DAD chromatogram of the polyphenol extract of pomegranate peel powder ((a) Beni Mellal, (c) Settat, (e) Berkane) and pomegranate seed powder ((b) Beni Mellal, (d) Settat, (f) Berkane). Phenolic compounds were detected at $280 \mathrm{~nm}$; the peaks were assigned to (1) gallic acid, (2) $\alpha$-punicalagin, (3) $\beta$-punicalagin, and (4) ellagic acid.

values, ranging from 1.29 to $2.17 \mathrm{mg} \mathrm{GAE} / \mathrm{g}$ of Chinapomegranate seeds, also for methanolic extracts [7].

In terms of total flavonoid contents found in Beni Mellal, Berkane, and Settat peel extracts, the values were 36,24 , and 25 -fold higher, respectively, than the content in seeds (Table 1). According to our study, the total flavonoids ranged from 52.13 to 62.64 and 1.76 to $2.11 \mathrm{mg}$ rutin/g dw in peel and seed, respectively; these values are higher than found by Orak et al. [11], where the content of flavonoids ranged from 14.37 to 20.52 and 5.92 to $16.92 \mathrm{rutin} / \mathrm{g} \mathrm{dw}$ in peel and seed, respectively. It is noteworthy that Beni Mellal pomegranate peels extracts contained the highest levels in comparison to Settat and Berkane.

The obtained flavonoids contents data confirms that the pomegranate peel fraction possesses the highest phenolic compounds, which totally agree with previous studies [34, 37]. Furthermore, statistical mean values showed that there is no significant $(p<0.05)$ differences between the three regions in terms of phenolic and flavonoid contents.

3.2. HPLC Quantitative Analysis. The ellagitannins are considered the most abundant polyphenols in pomegranate peel as its content can reach $66 \%$ of the total polyphenols in the peel [38]. The characterisation of the phenolic compounds present in the methanolic pomegranate extracts was performed using UHPLC. The qualitative-quantitative analysis of punicalagin anomers, gallic acid, and ellagic acid demonstrated that the concentrations of punicalagin isomers, gallic acid, and ellagic acid were lower in the seed compared to peel (Table 1). Moreover, the chromatographic patterns of the phenolic fraction show dominance of punicalagin- $\beta$ and punicalagin $\alpha$ in relation to other phenolic compounds, in both peel and seed extract (Figure 1).

Accordingly, polyphenolic analyses showed higher punicalagin content than the ellagic acid and gallic acid content in the peel and seed for the three regions, representing about 6- to 100-fold increase in relation to the gallic acid content. The pomegranate concentration of punicalagin might varied between 39.8 and $121.5 \mathrm{mg} / \mathrm{g} \mathrm{dw}$ [39], lower than our results that varied between 120.9 and $210.6 \mathrm{mg} / \mathrm{g} \mathrm{dw}$ (Table 1). In another study conducted by Masci et al. [37], concentrations of selected phenolic compounds in peel were determined to be $11.85-63.61 \mathrm{mg} / \mathrm{g}$ for ellagic acid and 7.39$41.36 \mathrm{mg} / \mathrm{g}$ for punicalagin- $\alpha$ and punicalagin- $\beta$. It must be 
TABLe 2: Antioxidant activities of pomegranate peel and seed.

\begin{tabular}{|c|c|c|c|c|c|}
\hline & & DPPH assay $\mathrm{EC}_{50}(\mu \mathrm{g} / \mathrm{mL})$ & ABTS assay $\mathrm{EC}_{50}(\mu \mathrm{g} / \mathrm{mL})$ & FRAP assay $\mathrm{mg} \mathrm{AA} / 100 \mathrm{~g} \mathrm{dw}$ & $\begin{array}{c}\mathrm{Fe}^{2+} \text { chelating activity } \\
(\mu \mathrm{mol} \text { EDTA equiv/g dw })\end{array}$ \\
\hline \multirow{3}{*}{ Peel } & Settat & $43.13 \pm 0.06^{\mathrm{a}}$ & $62.15 \pm 0.01^{\mathrm{a}}$ & $1.47 \pm 0.01^{\mathrm{a}}$ & $2.293 \pm 0.00^{\mathrm{a}}$ \\
\hline & Beni Mellal & $65.55 \pm 0.01^{\mathrm{b}}$ & $85.32 \pm 0.08^{\mathrm{b}}$ & $1.47 \pm 0.01^{\mathrm{a}}$ & $2.525 \pm 0.01^{\mathrm{a}}$ \\
\hline & Berkane & $42.71 \pm 0.04^{\mathrm{c}}$ & $65.47 \pm 0.14^{\mathrm{a}}$ & $1.855 \pm 0.00^{\mathrm{b}}$ & $1.401 \pm 0.00^{\mathrm{b}}$ \\
\hline \multirow{3}{*}{ Seed } & Settat & $888.29 \pm 0.02^{\mathrm{d}}$ & $4039.88 \pm 0.02^{\mathrm{c}}$ & $0.020 \pm 0.00^{c}$ & ND \\
\hline & Beni Mellal & $1945.13 \pm 0.03^{\mathrm{e}}$ & $4832.78 \pm 0.12^{\mathrm{d}}$ & $0.019 \pm 0.00^{c}$ & ND \\
\hline & Berkane & $1333.22 \pm 0.19^{\mathrm{f}}$ & $4215.56 \pm 0.08^{\mathrm{e}}$ & $0.012 \pm 0.00^{\mathrm{d}}$ & ND \\
\hline
\end{tabular}

Different letters of within the same column is indicating significant differences at $p<0.05$. All data are expressed as mean \pm SD of at least three replicates of each sample. dw: dry weight; AA: ascorbic acid.

TABLE 3: Correlation between polyphenol compositions antioxidant capacities.

\begin{tabular}{|c|c|c|c|c|c|c|c|c|c|c|}
\hline & $\begin{array}{c}\text { Total } \\
\text { polyphenols }\end{array}$ & $\begin{array}{c}\text { Total } \\
\text { flavonoids }\end{array}$ & Punicalagin- $\alpha$ & Punicalagin- $\beta$ & $\begin{array}{c}\text { Ellagic } \\
\text { acid }\end{array}$ & $\begin{array}{c}\text { Gallic } \\
\text { acid }\end{array}$ & $\begin{array}{c}\mathrm{DPPH} \\
\text { assay }\end{array}$ & $\begin{array}{l}\text { ABTS } \\
\text { assay }\end{array}$ & $\begin{array}{c}\mathrm{Fe}^{2+} \text { chelating } \\
\text { activity }\end{array}$ & $\begin{array}{l}\text { FRAP } \\
\text { assay }\end{array}$ \\
\hline $\begin{array}{l}\text { Total } \\
\text { polyphenols }\end{array}$ & 1.00 & & & & & & & & & \\
\hline Total flavonoids & .987 & 1.00 & & & & & & & & \\
\hline Punicalagin- $\alpha$ & .986 & .972 & 1.00 & & & & & & & \\
\hline Punicalagin- $\beta$ & .977 & .964 & .998 & 1.00 & & & & & & \\
\hline Ellagic acid & .995 & .988 & .994 & .987 & 1.00 & & & & & \\
\hline Gallic acid & .979 & .954 & .996 & .992 & .987 & 1.00 & & & & \\
\hline DPPH assay & -.908 & -.892 & -.908 & -.906 & -.908 & -.906 & 1.00 & & & \\
\hline ABTS assay & -.987 & -.975 & -.992 & -.988 & -.992 & -.988 & .949 & 1.00 & & \\
\hline $\begin{array}{l}\mathrm{Fe}^{2+} \text { chelating } \\
\text { activity }\end{array}$ & -.977 & -.966 & -.982 & -.978 & -.982 & -.981 & .947 & .995 & 1.00 & \\
\hline FRAP & .966 & .946 & .994 & .998 & .977 & .993 & -.898 & -.981 & -.972 & 1.00 \\
\hline
\end{tabular}

The results are expressed as Pearson's coefficient ( $p$ value).

noticed that these authors used an extraction procedure with ethanol, which provided a lower starting ellagic acid yield in relation to methanol at room temperature [25].

3.3. Antioxidant Activity Assessment. The antioxidant activity of pomegranate extracts was evaluated by two different radicals' assays, DPPH and ABTS (Table 2). Peel extracts demonstrated the strongest radical scavenging activity in relation to seed extracts, also reported by other research groups $[12,13,37]$. Antioxidant activity evaluated by DPPH assay of Beni Mellal, Settat, and Berkane pomegranate peel were 2.98-, 2.04-, and 3.16-fold higher than the respective seeds. Furthermore, a strong correlation was found between the total phenolic content of peel and seed and their respective radical scavenging activity (Table 3 ).

Commonly known, pomegranate peel polyphenolic compounds contribute to its powerful antioxidant activity. In fact, an extensive screening of 1,000 herbal plant extracts by Niwano et al. [40] revealed that pomegranate peel exhibits the strongest antioxidant activity. Panichayupakarananta et al. [39] studied the ellagic acid content and antioxidant activity in pomegranate fruit peel and found an $\mathrm{EC}_{50}$ $38 \mu \mathrm{g} / \mathrm{mL}$ in the methanolic extract, while in this work, the values varied between 42 and $65 \mu \mathrm{g} / \mathrm{mL}$ in peel and 888 and $1,945 \mu \mathrm{g} / \mathrm{ml}$ in seed. In contrast, a study by Liu et al. [41], evaluating the antioxidant properties of pulp and peel, showed that peel methanolic extract exhibits a lower scavenging activity $\left(\mathrm{EC}_{50} 12-25 \mathrm{mg} / \mathrm{mL}\right)$. Higher values $\left(\mathrm{EC}_{50} 0.84 \mathrm{mg} / \mathrm{mL}\right)$ were reported in comparison between edible and no edible pomegranates varieties in Tunisia [42]. A previous study by Khalil et al. [43] had also reported that fruit peel exhibited good scavenging activity using DPPH, their values varied between $63.36 \pm 3.20$ and $78.23 \pm 4.11 \%$.

Here, the antioxidant capacity by the ABTS method revealed lower antioxidant activity than that evaluated by the DPPH assay. Yet, the antioxidant activity of pomegranate peel was 6.5-fold higher than the one found in seed extracts (Table 2). These results are in agreement with those reported by Elfalleh et al. [44], with $\mathrm{EC}_{50}$ values of peel between 0.062 and $0.085 \mathrm{mg} / \mathrm{mL}$ and 4.03 and $4.83 \mathrm{mg} / \mathrm{mL}$ for seed extracts. Data from the ABTS assay showed a good correlation with the phenolic contents $(r=0.987, n=3)$ (Table 3 ).

ABTS and DPPH. Radicals scavenging activity of pomegranate peel and seed is attributed to their capacity of donating hydrogen from their hydroxyl group, thus neutralising free radicals by forming stable complexes. Commonly known, pomegranate peel compounds contribute to its antioxidant activity; previous studies mentioned the strong correlation between antioxidants activity and phenolic contents [25, 42].

3.4. FRAP Assay. The ferric reducing antioxidant power (FRAP) is a colorimetric method used to evaluate the 
antioxidant activity, different from previous methods, as it does not involve any free radical. This methodology is based on the reduction of the complex $\mathrm{Fe}^{+}$and ferricyanide complex to the ferrous form. The reducing power values expressed as mg ascorbic acid equivalent (AAE)/g of $\mathrm{dw}$ of peel or seed are shown in (Table 2). The values varied from 185.56 to $251.02 \mathrm{mg} \mathrm{AAE} / 100 \mathrm{~g}$ for peel, whereas seed showed valued between 0.12 and $0.20 \mathrm{mg}$ AAE/100 g, confirming the higher antioxidant capacity of the peel.

3.5. $\mathrm{Fe}^{+2}$ Chelating Activity. Metal chelation could provide important antioxidative effect by retarding metal catalysed oxidation of reactive oxygen species. In fact, phenolic compounds exhibit chelating effect when they are deprotonated [40]. As seen in Table 2, the metal chelating metal capacity of peel was found higher than seed. The data exhibited that metal chelating capacity ranged between 1.401 and $2.525 \mu \mathrm{mol}$ EDTA equiv/g dry weight in peel extract, whereas no significant chelating effect was found in seed. This finding could be explained by the small amount of total flavonoids presents in seeds. The strong correlation between flavonoid amounts in food samples and chelating ability has been demonstrated in literature, as an example, the quercetin has three metal binding sites [40].

\section{Conclusions}

In conclusion, in this study, pomegranates from three different regions in Morocco were analyzed for antioxidant activity and phenolic contents in peel and seed upon methanolic extraction. In the peel, punicalagin were the predominant compounds; also, gallic and ellagic acids were detected, which contribute to the significant correlation with the antioxidant activity. However, no significant difference of phenolic compounds or antioxidant activity was found between regions. The achieved results, in particular the high antioxidant capacity of pomegranate peel, suggest further application as natural food preservatives and as a health supplement rich in natural antioxidants.

\section{Data Availability}

The data used to support the findings of this study are included within the article.

\section{Conflicts of Interest}

The authors have declared no conflict of interest.

\section{Authors' Contributions}

A.E. and T.S. performed the conceptualization. A.E., T.S., and T.K performed the methodology. A.E., B.N., and A.M. performed the supervision. T.S. and T.K. wrote the original draft. R.D. and M.B wrote, reviewed, and edited the manuscript. All authors have read and agreed to the published version of the manuscript.

\section{Acknowledgments}

The authors wish many thanks to Dr.Sabrina GensbergerReigl from Friedrich-Alexander Universität Erlangen-Nürnberg, Germany, for her support in HPLC analysis.

\section{References}

[1] T. Ismail, P. Sestili, and S. Akhtar, "Pomegranate peel and fruit extracts: a review of potential anti-inflammatory and antiinfective effects," Journal of Ethnopharmacology, vol. 143, no. 2, pp. 397-405, 2012.

[2] J. A. Teixeira da Silva, T. S. Rana, D. Narzary, N. Verma, D. T. Meshram, and S. A. Ranade, "Pomegranate biology and biotechnology: A review," Scientia Horticulturae, vol. 160, pp. 85-107, 2013.

[3] Y. Li, C. Guo, J. Yang, J. Wei, J. Xu, and S. Cheng, "Evaluation of antioxidant properties of pomegranate peel extract in comparison with pomegranate pulp extract," Food Chemistry, vol. 96, no. 2, pp. 254-260, 2006.

[4] M. Viuda-Martos, J. Fernández-López, and J. A. Pérez-Álvarez, "Pomegranate and its Many Functional Components as Related to Human Health: A Review," Comprehensive Reviews in Food Science and Food Safety, vol. 9, no. 6, pp. 635-654, 2010.

[5] M. Aviram, L. Dornfeld, M. Rosenblat et al., "Pomegranate juice consumption reduces oxidative stress, atherogenic modifications to LDL, and platelet aggregation: studies in humans and in atherosclerotic apolipoprotein E-deficient mice," The American Journal of Clinical Nutrition, vol. 71, no. 5, pp. 1062-1076, 2000.

[6] F. Tezcan, M. Gültekin-Özgüven, T. Diken, B. Özçelik, and F. B. Erim, "Antioxidant activity and total phenolic, organic acid and sugar content in commercial pomegranate juices," Food Chemistry, vol. 115, no. 3, pp. 873-877, 2009.

[7] P. Jing, et al.T. Ye, H. Shi et al., "Antioxidant properties and phytochemical composition of China-grown pomegranate seeds," Food Chemistry, vol. 132, no. 3, pp. 1457-1464, 2012.

[8] U. A. Fischer, R. Carle, and D. R. Kammerer, "Identification and quantification of phenolic compounds from pomegranate (Punica granatum L.) peel, mesocarp, aril and differently produced juices by HPLC-DAD-ESI/MSn," Food Chemistry, vol. 127, no. 2, pp. 807-821, 2011.

[9] S. Akhtar, T. Ismail, D. Fraternale, and P. Sestili, "Pomegranate peel and peel extracts: chemistry and food features," Food Chemistry, vol. 174, pp. 417-425, 2015.

[10] B. Singh, J. P. Singh, A. Kaur, and N. Singh, "Phenolic compounds as beneficial phytochemicals in pomegranate (Punica granatum L.) peel: A review," Food Chemistry, vol. 261, pp. 75-86, 2018.

[11] H. H. Orak, H. Yagar, and S. S. Isbilir, "Comparison of antioxidant activities of juice, peel, and seed of pomegranate (Punica granatum L.) and inter-relationships with total phenolic, Tannin, anthocyanin, and flavonoid contents," Food Science and Biotechnology, vol. 21, no. 2, pp. 373-387, 2012.

[12] Z. Derakhshan, M. Ferrante, M. Tadi et al., "Antioxidant activity and total phenolic content of ethanolic extract of pomegranate peels, juice and seeds," Food and Chemical Toxicology, vol. 114, pp. 108-111, 2018.

[13] M. Dikmen, N. Ozturk, and Y. Ozturk, "The antioxidant potency of Punica granatum L. fruit peel reduces cell 
proliferation and induces apoptosis on breast cancer," Journal of Medicinal Food, vol. 14, no. 12, pp. 1638-1646, 2011.

[14] B. Song, J. Li, and J. Li, "Pomegranate peel extract polyphenols induced apoptosis in human hepatoma cells by mitochondrial pathway," Food and Chemical Toxicology, vol. 93, pp. 158-166, 2016.

[15] S. Radhika, K. H. Smila, and R. Muthezhilan, “Antidiabetic and hypolipidemic activity of Punica granatum linn on alloxan induced rats," World Journal of Medical Sciences, vol. 6, no. 4, pp. 178-182, 2011.

[16] B. M. Naveena, A. R. Sen, S. Vaithiyanathan, Y. Babji, and N. Kondaiah, "Comparative efficacy of pomegranate juice, pomegranate rind powder extract and BHT as antioxidants in cooked chicken patties," Meat Science, vol. 80, no. 4, pp. 1304-1308, 2008.

[17] M. M. El-Said, H. F. Haggag, H. M. Fakhr El-Din, A. S. Gad, and A. M. Farahat, "Antioxidant activities and physical properties of stirred yoghurt fortified with pomegranate peel extracts," Annals of Agriculture Sciences, vol. 59, no. 2, pp. 207-212, 2014.

[18] L. He, H. Xu, X. Liu et al., "Identification of phenolic compounds from pomegranate (Punica granatum L.) seed residues and investigation into their antioxidant capacities by HPLC$\mathrm{ABTS}^{+}$assay," Food Research International, vol. 44, no. 5, pp. 1161-1167, 2011.

[19] N. Z. Shaban, M. A. L. el-Kersh, F. H. el-Rashidy, and N. H. Habashy, "Protective role of Punica granatum (pomegranate) peel and seed oil extracts on diethylnitrosamine and phenobarbital-induced hepatic injury in male rats," Food Chemistry, vol. 141, no. 3, pp. 1587-1596, 2013.

[20] M. A. Shabbir, M. R. Khan, M. Saeed, I. Pasha, A. A. Khalil, and N. Siraj, "Punicic acid: a striking health substance to combat metabolic syndromes in humans," Lipids in Health and Disease, vol. 16, no. 1, p. 99, 2017.

[21] J. J. Martínez, F. Hernández, H. Abdelmajid et al., "Physicochemical characterization of six pomegranate cultivars from Morocco: processing and fresh market aptitudes," Scientia Horticulturae, vol. 140, pp. 100-106, 2012.

[22] E. A. Ajal, R. Jbir, P. Melgarejo, F. Hernández, A. Haddioui, and A. S. Hannachi, "Efficiency of Inter Simple Sequence Repeat (ISSR) markers for the assessment of genetic diversity of Moroccan pomegranate (Punica granatum L.) cultivars," Biochemical Systimatics ans Ecology, vol. 56, pp. 24-31, 2014.

[23] I. Hmid, D. Elothmani, H. Hanine, A. Oukabli, and E. Mehinagic, "Comparative study of phenolic compounds and their antioxidant attributes of eighteen pomegranate (Punica granatum L.) cultivars grown in Morocco," Arabian Journal of Chemistry, vol. 10, pp. S2675-S2684, 2017.

[24] P. Legua, P. Melgarejo, H. Abdelmajid et al., “Total phenols and antioxidant capacity in 10 moroccan pomegranate varieties," Journal of Food Science, vol. 77, no. 1, pp. C115-C120, 2012.

[25] R. P. Singh, K. N. Chidambara Murthy, and G. K. Jayaprakasha, "Studies on the antioxidant activity of pomegranate (Punicagranatum) peel and seed extracts using in vitro models," Journal of Agricultural and Food Chemistry, vol. 50, no. 1, pp. 81-86, 2002.

[26] J. Zhishen, T. Mengcheng, and W. Jianming, "The determination of flavonoid contents in mulberry and their scavenging effects on superoxide radicals," Food Chemistry, vol. 64, no. 4, pp. 555-559, 1999.
[27] X. Li, L. Liu, and M. Pischetsrieder, "Pomegranate (Punica granatum L.) wine polyphenols affect $\mathrm{Nrf} 2$ activation and antioxidant enzyme expression in human neuroblastoma cells (SH-SY5Y)," Journal of Functional Foods, vol. 38, pp. 140150, 2017.

[28] I. I. Ramos, B. J. R. Gregório, L. Barreiros et al., "Programmable flow system for automation of oxygen radical absorbance capacity assay using pyrogallol red for estimation of antioxidant reactivity," Talanta, vol. 150, pp. 599-606, 2016.

[29] M. Oyaizu, "Studies on products of browning reaction. Antioxidative activities of products of browning reaction prepared from glucosamine," Japanese Journal of Nutrients and Dietetics, vol. 44, no. 6, pp. 307-315, 1986.

[30] T. C. P. Dinis, V. M. C. Madeira, and L. M. Almeida, “Action of phenolic Derivatives (Acetaminophen, Salicylate, and 5-Aminosalicylate) as inhibitors of membrane lipid peroxidation and as Peroxyl Radical scavengers," Archives of Biochemistry and Biophysics, vol. 315, no. 1, pp. 161-169, 1994.

[31] T. M. Rababah, F. Banat, A. Rababah, K. Ereifej, and W. Yang, "Optimization of extraction conditions of total phenolics, antioxidant activities, and anthocyanin of oregano, thyme, terebinth, and pomegranate," Journal of Food Science, vol. 75, no. 7, pp. C626-C632, 2010.

[32] Z. Wang, "Extract of phenolics from pomegranate peels," The Open Food Science Journal., vol. 5, no. 1, pp. 17-25, 2011.

[33] C. Pagliarulo, V. de Vito, G. Picariello et al., "Inhibitory effect of pomegranate (Punica granatum L.) polyphenol extracts on the bacterial growth and survival of clinical isolates of pathogenic Staphylococcus aureus and Escherichia coli," Food Chemistry, vol. 190, pp. 824-831, 2016.

[34] E. Mansour, A. Ben Khaled, B. Lachiheb, M. Abid, K. Bachar, and A. Ferchichi, "Phenolic compounds, antioxidant, and antibacterial activities of peel extract from Tunisian pomegranate," Journal of Agriculture Science and Technology, vol. 15, pp. 1393-1403, 2013.

[35] P. Ambigaipalan, A. C. De Camargo, and F. Shahidi, "Phenolic compounds of pomegranate byproducts (outer skin, mesocarp, divider membrane) and their antioxidant activities," Journal of Agriculture and Food Chemistry, vol. 64, no. 34, pp. 6584-6604, 2016.

[36] A. A. Khalil, M. R. Khan, M. A. Shabbir, and K. U. Rahman, "In vitro antioxidant activity and punicalagin content quantification of pomegranate peel obtained as agro-waste after juice extraction," Pakistan Journal of Agricultural Sciences, vol. 55, no. 1, pp. 197-201, 2018.

[37] A. Masci, A. Coccia, E. Lendaro, L. Mosca, P. Paolicelli, and S. Cesa, "Evaluation of different extraction methods from pomegranate whole fruit or peels and the antioxidant and antiproliferative activity of the polyphenolic fraction," Food Chemistry, vol. 202, pp. 59-69, 2016.

[38] Y.-q. Sun, X. Tao, X.-m. Men, Z.-w. Xu, and T. Wang, "In vitro and in vivo antioxidant activities of three major polyphenolic compounds in pomegranate peel : Ellagic acid, punicalin, and punicalagin," Journal of Integrative Agriculture, vol. 16, no. 8, pp. 1808-1818, 2017.

[39] P. Panichayupakarananta, A. Issuriya, A. Sirikatitham, and W. Wang, "Antioxidant Assay-Guided Purification and LC Determination of Ellagic Acid in Pomegranate Peel," Journal of Chromatographic Science, vol. 48, no. 6, pp. 456-459, 2010.

[40] H. Khodr, "Metal Chelation of Polyphenols Metal Chelation of Polyphenols," Methods in Enzymology, vol. 6879, pp. 190-203, 2018. 
[41] H. Liu, J. Cao, and W. Jiang, "Evaluation and comparison of vitamin $\mathrm{C}$, phenolic compounds, antioxidant properties and metal chelating activity of pulp and peel from selected peach cultivars," LWT - Food Science and Technology, vol. 63, no. 2, pp. 1042-1048, 2015.

[42] Z. Amri, F. Zaouay, H. Lazreg-Aref et al., "Phytochemical content, fatty acids composition and antioxidant potential of different pomegranate parts: comparison between edible and non edible varieties grown in Tunisia," International Journal of Biological Macromolecules, vol. 104, Part A, pp. 274-280, 2017.

[43] A. A. Khalil, M. R. Khan, M. A. Shabbir, and K. U. Rahman, "Comparison of antioxidative potential and punicalagin content of pomegranate peels," Journal of Animal and Plant Science, vol. 27, no. 2, pp. 522-527, 2017.

[44] W. Elfalleh, "Total phenolic contents and antioxidant activities of pomegranate peel, seed, leaf and flower," Journal of Medicinal Plants Resarch, vol. 6, no. 32, pp. 4724-4730, 2012. 